\title{
Mapping the A Genome for QTL Conditioning Resistance to Fusarium Head Blight in a Wheat Population with Triticum timopheevii Background
}

\begin{abstract}
Ali Malihipour, Department of Biological Sciences, University of Manitoba, Winnipeg, MB R3T 2N2, Canada, and Cereal Research Centre, Agriculture and Agri-Food Canada, Winnipeg, MB R3T 2M9, Canada; Jeannie Gilbert, Cereal Research Centre, Agriculture and Agri-Food Canada, Winnipeg; George Fedak, Eastern Cereal and Oilseed Research Centre, Agriculture and Agri-Food Canada, Ottawa, ON K1A 0C6, Canada; Anita Brûlé-Babel, Department of Plant Science, University of Manitoba, Winnipeg; and Wenguang Cao, Eastern Cereal and Oilseed Research Centre, Agriculture and Agri-Food Canada, Ottawa
\end{abstract}

\begin{abstract}
Development and use of resistant wheat cultivars is the most practical and economical approach for the control of Fusarium head blight (FHB). In the present study, a population of recombinant inbred lines derived from the cross between 'AC Brio' (a Canadian bread wheat cultivar moderately susceptible to FHB) and 'TC 67' (an FHB-resistant cultivar derived from Triticum timopheevii) was used to map quantitative trait loci (QTL) for FHB resistance using microsatellite molecular markers. Multiple interval mapping detected several QTL for FHB resistance on the chromosomes 5AL and 6A. The QTL detected in the marker interval of cfd6.1-barc48 on chromosome 5AL explained 10.9, 5.2, and 7.8\% of phenotypic variation for disease incidence (type I resistance), disease severity (a combination of type I and type II resistance), and Fusarium-damaged kernels (FDK) (type IV resistance) under field conditions, respectively. The second QTL mapped

to $5 \mathrm{AL}$, in the marker interval of $c f d 39$-cfa2185, explained 19.4 and $20.6 \%$ of phenotypic variation for FDK under field conditions and disease severity in the greenhouse (type II resistance), respectively. The QTL located on chromosome $6 \mathrm{~A}$ conferred resistance to disease incidence and severity under field conditions and to disease severity in the greenhouse, explaining 6.8 to $11.8 \%$ of phenotypic variation for these traits. Several QTL for agronomic traits were also mapped in this study, including one and two QTL to the chromosomes 2A and 5AL, respectively, all for plant height, and two QTL to chromosome $6 \mathrm{~A}$ for plant height and flowering date, respectively. The 5AL QTL for FHB resistance mapped in the marker interval of $c f d 39-c f a 2185$ in the present study is a novel QTL that originated from T. timopheevii and is reported here for the first time. Further validation of this QTL is required for wheat breeding programs to enhance resistance levels to FHB.
\end{abstract}

Fusarium head blight (FHB) is one of the most destructive diseases of wheat worldwide. The disease is caused mainly by Fusarium graminearum sensu lato but other species, including $F$. culmorum and $F$. avenaceum, are also important in some wheat-growing regions (Parry et al. 1995). Infection occurs primarily during flowering and may lead to severe yield reduction and decreased grain quality (Bai and Shaner 1994). Development of resistant cultivars is an important tool for mitigation of FHB (Yang et al. 2005). The Chinese FHBresistant wheat 'Sumai 3' and its derivatives, including 'Ning7840', have been successfully used as a resistant parent in many wheat breeding programs worldwide (Bai and Shaner 2004). Other sources of resistance, including 'Shinchunaga', 'Nobeokabouzu', and 'Nyu Bai' from Japan; 'Frontana' and 'Encruzilhada' from Brazil; and 'Ernie' and 'Freedom' from the United States have also been used in breeding programs in several countries (Bai and Shaner 2004). Since 2000, several FHB-resistant wheat cultivars such as 'SteeleND' (Mergoum et al. 2005), 'ND 2710' (Frohberg et al. 2004), 'Glenn' (Mergoum et al. 2006), and 'VA04W-433' and 'VA04W474' (Chen et al. 2012) from the United States; 'TC 67' (Cao et al. 2009) and 'Waskada' (Fox et al. 2009) from Canada; and 'Morvarid' from Iran (A. Malihipour, unpublished) were released and grown on a commercial scale. However, breeding wheat for resistance to FHB

Present address of A. Malihipour: Cereal Research Department, Seed \& Plant Improvement Institute (SPII), Agricultural Research, Education, and Extension Organization, Shahid Fahmideh Blvd., P.O. Box 31585-4119, Karaj, Alborz, Iran

Corresponding author: A. Malihipour; E-mail: a.malihipour@gmail.com

Accepted for publication 16 September 2016.

(c) 2017 The American Phytopathological Society is difficult because of the polygenic nature of resistance, complex genetic inheritance, genotype-environment interactions, and the high cost of phenotyping (Bai and Shaner 1994; McMullen et al. 1997; Somers et al. 2003; Yang et al. 2005).

Five types of resistance to FHB have been proposed: resistance to initial infection or type I resistance (Schroeder and Christensen 1963); resistance to spread of infection within the spike or type II resistance (Schroeder and Christensen 1963); ability to prevent synthesis of deoxynivalenol (DON) or promote degradation of the produced DON (Miller et al. 1985) and tolerance of high DON concentrations (Wang and Miller 1988), which are referred together as resistance to toxin accumulation, or type III resistance in more recent literature (Mesterházy et al. 1999); resistance to kernel infection or type IV resistance (Mesterházy 1995; Mesterházy et al. 1999); and disease tolerance (Mesterházy 1989, 1995; Mesterházy et al. 1999). Type I resistance is determined by spraying a spore suspension onto flowering spikes and measuring percentage of diseased spikes, which is commonly referred to as disease incidence (Buerstmayr et al. 2009). Type II resistance, which is determined based on the proportion of diseased spikelets (frequently referred to as disease severity) from central-floret inoculation (Bai et al. 1999; Waldron et al. 1999), has been extensively studied in wheat, because it appears to be more stable and less affected by nongenetic factors (Bai and Shaner 1994). However, disease severity assessed under spray-inoculated field experiments is used as a measure of overall FHB resistance (Buerstmayr et al. 2009), because both type I and type II resistance are considered. Type III resistance is determined by assessing DON accumulation in kernels using different methods such as chromatography or enzyme-linked immunosorbent assay (ELISA). Finally, type IV resistance is often measured by determining the proportion of Fusarium-damaged kernels (FDK).

Resistance to FHB in wheat is quantitatively inherited and the underlying quantitative trait loci (QTL) are distributed throughout the wheat genome. Six QTL conferring resistance to FHB have been formally named as genes $F h b 1, F h b 2, F h b 3, F h b 4, F h b 5$, and 
Fhb6. Fhb1, present on chromosome 3BS from Sumai 3 and its derivatives (Liu et al. 2006), is the most consistent gene with the largest effect on type II resistance identified to date (Buerstmayr et al. 2009). This gene also reduces disease incidence (Chen et al. 2006; Yang et al. 2005), disease severity (Buerstmayr et al. 2003a; Jia et al. 2005; Mardi et al. 2005; Szabó-Hevér et al. 2014), FDK (Suzuki et al. 2012; Szabó-Hevér et al. 2014; Yang et al. 2005), and DON accumulation (Jiang et al. 2007; Lemmens et al. 2005; Somers et al. 2003; Suzuki et al. 2012; Szabó-Hevér et al. 2014; Yu et al. 2008; Zhou et al. 2002). Fhbl is now extensively used in wheat breeding programs due to its stable major effect on type II resistance across different genetic backgrounds (Buerstmayr et al. 2009). Several QTL specifically associated with resistance to fungal penetration (type I resistance) such as Qfhs.ifa-5A from 'CM-82036' (Buerstmayr et al. 2003a,b), Qfhi.nau-4B and Qfhi.nau-5A from 'Wangshuibai' (Lin et al. 2006), a major QTL mapped to chromosome 3A from Frontana (Steiner et al. 2004), and a few QTL from the Sumai 3-derived line 'DH181' (Yang et al. 2005) have also been reported. These QTL have a strong effect on resistance expression.

Several wheat-related species such as Elymus humidus (Ohwi et Sakamoto) Osada, E. racemifer (Steud.) Tzvel., Roegneria kamoji, and Leymus racemosus (Lam.) Tzvel. are potential donors of FHB resistance genes (Chen et al. 2005; Oliver et al. 2005). However, the resistance found in related species is usually associated with undesirable traits which are difficult to remove from the progeny (Bai and Shaner 2004). Special chromosome manipulation is needed to introgress FHB resistance genes into wheat from distantly related species (Cai et al. 2005). Resistance to FHB has also been identified in tetraploid wheat species such as wild emmer wheat (Triticum turgidum L. subsp. dicoccoides (Körn ex Asch. et Graebn.) Thell.) (Oliver et al. 2007), cultivated emmer wheat (T. turgidum L. subsp. dicoccum (Schrank ex Schübl.) Thell.), and Persian wheat (T. turgidum L. subsp. carthlicum (Nevski) A. Löve et D. Löve) (Cai et al. 2005; Oliver et al. 2008; Somers et al. 2006). T. timopheevii (Zhuk.) Zhuk., which is another tetraploid wheat, has a high level of resistance to FHB (Cao et al. 2009). The FHB resistance present in T. timopheevii, which may be of novel resistance, is not clearly understood yet. Mapping and tagging of FHB resistance available in wheat cultivars with a background of T. timopheevii may be of great interest for use in wheat breeding programs. The objectives of this study were to (i) map FHB resistance QTL in a population of wheat derived from T. timopheevii, (ii) detect simple sequence repeat (SSR) molecular markers linked to these QTL in this population, and (iii) determine the novelty of these QTL in comparison with other available resistance sources.

\section{Materials and Methods}

Plant materials. In an attempt to enhance FHB resistance in bread wheat, several wheat-related wild species, including a number of T. timopheevii $(2 n=4 x=28$, AAGG) lines, were screened for FHB resistance (Cao et al. 2009). An FHB-resistant accession of T. timopheevii, PI 343447, was crossed to the susceptible spring wheat 'Crocus' (T. aestivum, $2 n=6 x=42$, AABBDD). The resulting $\mathrm{F}_{1}$ plants were backcrossed to Crocus to produce $\mathrm{BC}_{1} \mathrm{~F}_{1}$ plants $(2 n=$ $6 x=42$, AABBDD). A population of $1,500 \mathrm{~F}_{2}$ plants was established and $535 \mathrm{BC}_{1} \mathrm{~F}_{7}$ lines were developed using single-seed descent (SSD). In total, 100 lines were selected on the basis of plant fertility and agronomic traits, and were evaluated for reaction to FHB in the greenhouse and field FHB nursery. TC 67 was selected from this population on the basis of its superior FHB reaction and reasonable agronomic traits (Cao et al. 2009). Later, the moderately susceptible wheat 'Brio' ( $T$. aestivum, $2 n=6 x=42$, AABBDD), with the pedigree of 'Columbus'/'S68147'//'Laval19'/Columbus, was crossed to TC 67. An $\mathrm{F}_{7}$ mapping population consisting of 230 recombinant inbred lines (RIL) developed using SSD from the cross of Brio and TC 67 was used in this study.

Fusarium isolates and inoculum production. A mixture of F. graminearum isolates (40/04, 71/04, 98/04, 136/04, MSDS 3/03, and EMMB 19/03) stored at the Cereal Research Centre (CRC), Winnipeg, Manitoba, Canada, was used for the field inoculations in
Carman, Manitoba. The same isolates were used in Glenlea, Manitoba, with the exception that the last two isolates were replaced with two other isolates (M1-04-5 and M3-04-3). For inoculum production, actively growing cultures of the isolate on potato dextrose agar (PDA) were blended, added to liquid carboxymethyl cellulose sodium culture media (Sigma-Aldrich, St. Louis), and incubated under aeration for 5 to 7 days at room temperature. The culture media was passed through a cheesecloth and the suspension was diluted to $5 \times$ $10^{4}$ macroconidia/ $\mathrm{ml}$ before the field inoculations.

For the greenhouse studies, a mixture of four highly aggressive isolates (M6-04-4, M9-04-6, M1-04-1, and M8-04-3) was used. The method used by Afshari-Azad (1992) was modified as follows and used for the greenhouse inoculum production: $5 \mathrm{~g}$ of blended straw from wheat or barley was added to $125 \mathrm{ml}$ of tap water in a 250-ml flask and autoclaved two times with a 24-h interval, a small plug of PDA (Difco, Sparks, MD) containing the fungal isolate was added to the culture, and the culture was shaken for $96 \mathrm{~h}$ at $120 \mathrm{rpm}$ at room temperature. Like the field inoculations, the culture was passed through a cheesecloth and the suspension was diluted for inoculations.

Field experiments. The mapping population and the parental lines were evaluated for FHB in spray-inoculated field trials conducted in two locations, Carman and Glenlea, Manitoba, Canada, for 2 years (2006 and 2007). The experimental design was a randomized complete block design in both locations in 2006 and a 16-by-15 lattice design in 2007, each with three replications. Plots consisted of rows $1 \mathrm{~m}$ (Carman) or $1.5 \mathrm{~m}$ (Glenlea) in length, with $30-\mathrm{cm}$ row spacing. Sowing density was approximately $5 \mathrm{~g}$ of seed per plot. Sowing dates were 29 to 30 May and 5 June in Carman and Glenlea, respectively, in 2006, and 9 May in both locations in 2007. Standard procedures were used to maintain the nurseries, and control weeds and insects. 'Roblin' wheat was used as the susceptible check to monitor disease level in the nurseries.

Plots were spray inoculated individually when $50 \%$ of the plants had reached anthesis with a conidial suspension of the pathogen isolates $\left(5 \times 10^{4}\right.$ macroconidia $\left./ \mathrm{ml}\right)$ using a $\mathrm{CO}_{2}$-powered backpack sprayer till runoff of the inoculum on the plants. The inoculation procedure was repeated 2 or 3 days later. Nurseries were mist irrigated $5 \mathrm{~min} / \mathrm{h}$ (Carman) for $12 \mathrm{~h}$ or sprinkler irrigated for $1 \mathrm{~h}$ (Glenlea) after inoculation. After the first day of inoculation, the irrigation system was operated two to three times a day, until the disease developed in the nurseries.

Three weeks after inoculation, the RIL were scored for disease incidence and severity. Disease incidence was determined as the percentage of diseased spikes per plot and disease severity according to a scale of 0 to $100 \%$ for the visually infected spikelets on a whole-plot basis. To score the RIL for FDK, rows were sickle harvested at maturity and threshed using a Wintersteiger Nursery Master Elite combine (Wintersteiger AG, Ried, Austria). The threshing mechanism was set at a normal setting on the combine; however, the wind speed was decreased and sieves were opened to ensure that FDK were retained in the harvested samples. A wheat head thresher (Precision Machine Co. Inc., Lincoln, NE) later was used to thresh wheat samples, which were not well threshed. FDK were assessed by counting the visually damaged kernels in three random subsamples of 100 grains from each plot.

Data of agronomic traits, including flowering date and plant height, were also collected under field conditions. Flowering date was measured as the number of days from seeding to $50 \%$ anthesis of the plot and plant height as the distance from soil surface to top of the spikes minus awns at growth stages 65 and 91, respectively, according to Zadoks et al. (1974).

Greenhouse experiments. The RIL were evaluated for resistance to fungal spread within the spike (disease severity) following singlefloret inoculation in the greenhouses in Winnipeg in 2007. The experimental layout was a randomized complete block design with three replicates, and each pot (16 by 13 by $13 \mathrm{~cm}^{3}$ ) was an experimental plot. The greenhouse was maintained under conditions of $16 \mathrm{~h}$ of light and $8 \mathrm{~h}$ of darkness. The temperature of the greenhouse averaged $24^{\circ} \mathrm{C}$ during the day, with a range of 18 to $28^{\circ} \mathrm{C}$, and $18^{\circ} \mathrm{C}$ at night, with a range of 16 to $20^{\circ} \mathrm{C}$. Wheat plants were treated 3 weeks after seeding with a mixture of propiconazole + spinosad 
to control powdery mildew and insects. As in the field experiments, Roblin was used as the susceptible check.

The RIL varied in flowering date. As spikes reached 50\% anthesis, they were inoculated using a micropipette to inject $10 \mu \mathrm{l}$ of conidial suspension of $F$. graminearum isolates $\left(5 \times 10^{4}\right.$ macroconidia/ml) into the floret in a spikelet positioned one-third of the way from the top of the spike. At least five spikes in each pot (replication) were inoculated, and the spikes were covered with a glassine bag ( 20 by $5 \mathrm{~cm}^{2}$; Seedburo Equipment Co., Chicago) for $48 \mathrm{~h}$ to maintain constant high humidity. Disease severity in the inoculated spikes was measured as the percentage of diseased spikelets per spike 21 days after inoculation. The greenhouse experiment was conducted twice.

Measurements were also taken for plant height and flowering date. Plant height was measured as mentioned for the field data and flowering date as the average number of days from seeding date to anthesis for the first five early-emerging spikes.

Marker analysis. In total, 323 SSR primer combinations stored at the CRC, including barc (Song et al. 2002, 2005), cfa, $c f d$ (Guyomarc'h et al. 2002; Sourdille et al. 2003), gdm, gwm (Pestsova et al. 2000; Röder et al. 1998), and $w m c$ (Gupta et al. 2002), were used for marker analysis. We used these markers, all from the 'A' genome, because, most likely, the resistance introgressed from T. timopheevii ( $2 n=4 x=28$, AAGG) into TC 67 was expected to be on this genome. They covered a total length of 1,778 centimorgans (cM) with an average distance of $2.77 \mathrm{cM}$ between the markers based on the microsatellite consensus map for bread wheat (Schuelke 2000; Somers et al. 2004). For polymerase chain reaction (PCR) amplification, forward primers tailed with a 19-bp fluorescent-labeled M13 primer (5'-CACGACGTTGTAAAACGAC) at the $5^{\prime}$ end were used. A universal fluorescent-labeled M13 primer homologous to the same sequence added to each forward primer was also added to the PCR (Schuelke 2000; Somers et al. 2004). Reverse primers used in the reaction were normal. The PCR was performed in a $10-\mu l$ volume, containing $5 \mu \mathrm{l}$ of template DNA at $10 \mathrm{ng} / \mu \mathrm{l} ; 1.5 \mathrm{mM} \mathrm{MgCl}_{2} ; 0.8 \mathrm{mM}$ each dNTP (Invitrogen, Carlsbad, CA); forward primer at $0.02 \mathrm{pmol} / \mu \mathrm{l}$; reverse primer at $0.2 \mathrm{pmol} / \mu \mathrm{l}$ (Invitrogen); M13 primer fluorescently labeled with FAM, HEX, or NED at $1.8 \mathrm{pmol} / \mu \mathrm{l}$ (Applied Biosystems, Foster City, CA); $1 \times$ PCR buffer; and Taq DNA polymerase at $1 \mathrm{unit} / \mu \mathrm{l}$. The PCR products were amplified in a PTC-200 thermal cycler (MJ Research, Waltham, MA) with the following cycling program: (i) $94^{\circ} \mathrm{C}$ for $2 \mathrm{~min}$ (initial denaturing step); (ii) $31 \mathrm{cy}-$ cles of $95^{\circ} \mathrm{C}$ for $1 \mathrm{~min}$ (for DNA denaturation), $0.5^{\circ} \mathrm{C} / \mathrm{s}$ to 51 or $61^{\circ} \mathrm{C}$, 51 or $61^{\circ} \mathrm{C}$ for $30 \mathrm{~s}$ (for primer annealing), $0.5^{\circ} \mathrm{C} / \mathrm{s}$ to $73^{\circ} \mathrm{C}$, and $73^{\circ} \mathrm{C}$ for $1 \mathrm{~min}$ (for primer extension); (iii) $73^{\circ} \mathrm{C}$ for $5 \mathrm{~min}$ (for final extension); and (iv) $4{ }^{\circ} \mathrm{C}$ to hold the program. PCR products were multiplexed by combining $0.5 \mu \mathrm{l}$ of FAM-, $0.6 \mu \mathrm{l}$ of HEX-, and $0.5 \mu \mathrm{l}$ of NED-labeled products with $5.0 \mu \mathrm{l}$ of a $4 \%$ mixture of GeneScan 500-ROX (Applied Biosystems) in Hi-Di formamide (Applied Biosystems). The multiplex was denatured for $10 \mathrm{~min}$ at $95^{\circ} \mathrm{C}$ and quickly chilled on ice for $5 \mathrm{~min}$. The denatured sample was loaded on an ABI PRISM 3130xl Genetic Analyzer (Applied Biosystems) and fragment analysis was performed with GeneScan 3.7.1 (Applied Biosystems). Data collected by fluorescent capillary electrophoresis was converted to a gel-like image using Genographer 2.0 (Benham et al. 1999) (freely available at http://sourceforge.net/projects/genographer). The images were formatted using Canvas 11 (ACD Systems of America Inc., Fort Lauderdale, FL) and the final images were printed and scored manually.

All primers were screened for polymorphism on the two parents, and those which produced polymorphic fragments between the parental samples were used to genotype the entire mapping population. The $\chi^{2}$ test was employed to estimate segregation distortion for the markers in the population.

The linkage maps for marker data were created using JoinMap V 3.0 (Van Ooijen and Voorrips 2001). A Kosambi map function (Kosambi 1943) was applied to calculate the distance between the ordered markers. Linkage groups were established using a minimum logarithm of odds (LOD) threshold of 2.0. The maps were compared with the wheat consensus SSR map (Schuelke 2000; Somers et al.
2004) available in the GrainGenes database (http://wheat.pw.usda. gov/ggpages/maps.shtml).

Analysis of field and greenhouse data. Data collected from the six environments (two field locations in 2 years plus two greenhouse experiments) were used for data analysis. Combined data from four environments were used for estimating correlations and analyses of variance (ANOVA) under field conditions. For the greenhouse experiments, a combined data set of disease severity obtained from two experiments was used for the analysis. Before conducting ANOVA, the field and greenhouse data sets were tested for normality using PROC UNIVARIATE of SAS. In the event that the residuals of the dependent variables did not follow a normal distribution, an arcsine transformation was applied to data. ANOVA were performed using PROC GLM based on a randomized complete block design. Genotype effect in the statistical model was considered fixed, while the other effects were considered random. Broadsense heritabilities for the RIL were estimated from ANOVA (Hallauer and Miranda 1981) using the formulae $h^{2}=\sigma_{G}^{2} /\left[\sigma_{G}^{2}+\left(\sigma_{e}^{2} / r\right)\right]$ for the single-location or greenhouse, $h^{2}=\sigma_{G}^{2} /\left[\sigma_{G}^{2}+\left(\sigma_{G L}^{2} / l\right)+\left(\sigma_{e}^{2} / r l\right)\right]$ for the combined data of two locations or greenhouses, and $h^{2}=\sigma_{G}^{2} /\left[\sigma_{G}^{2}+\left(\sigma_{G L}^{2} / l\right)+\left(\sigma_{G Y}^{2} / y\right)+\left(\sigma_{G Y L}^{2} / y l\right)+\left(\sigma_{e}^{2} / r y l\right)\right]$ for the combined data of two locations in 2 years, where $\sigma_{G}^{2}$ is the genotypic variance, $\sigma_{G L}^{2}$ is genotype-location variance, $\sigma_{G Y}^{2}$ is genotype-year variance, $\sigma_{G Y L}^{2}$ is genotype-location-year variance, $\sigma_{e}^{2}$ is residual variance, $r$ is the number of replications (blocks), $l$ is the number of locations, and $y$ is the number of years. All statistical analyses were performed using SAS 9.2 (SAS Institute Inc., Raleigh, NC).

QTL mapping. Before QTL analysis, data transformations were applied to phenotypic data if necessary. QTL analysis was conducted using the computer program QGene V 4.3.10 (Joehanes and Nelson 2008). The single-trait multiple IM option of this software was performed to detect genomic regions on linkage groups associated with phenotypic means. A LOD threshold of 2 was used to declare a QTL significant. However, the significance was determined based on a permutation test of $n=1,000$ (Churchill and Doerge 1994). For each QTL, the marker, the percentage of phenotypic variation explained, and the additive effects were estimated. The single-marker regression option of QGene was also applied to detect association between single markers and phenotypic data.

\section{Results}

FHB resistance. Results from the ANOVA using the combined field data of two locations in 2 years showed significant differences among the RIL and significant location-genotype interaction $(P \leq$ 0.05 ) for disease incidence and FDK but not for disease severity (data not shown). On the other hand, the interactions of year-genotype and year-location-genotype were significant $(P \leq 0.05)$ for all FHB resistance traits studied (data not shown). For the greenhouse data of disease severity, ANOVA showed significant differences $(P \leq$ 0.01 ) among the RIL as well (data not shown).

Based on the FHB traits measured, 'AC Brio' wheat was more susceptible than TC 67 to FHB (Table 1). A high range of variation was observed among the RIL for disease incidence, severity, and FDK under field conditions and for disease severity in the greenhouse (Table 1). The frequency distributions for all traits were continuous and showed transgressive segregation (Fig. 1).

Broad-sense heritability, which measures the proportion of the phenotypic variance that is due to genetic effects, was highest for disease severity in the greenhouse and lowest for disease severity under field conditions. Intermediate heritability values were observed for disease incidence and FDK under field conditions (Table 1).

Correlations among FHB resistance traits. All correlation coefficients among the FHB resistance traits estimated using the field and greenhouse data were positive and significant $(P \leq 0.01)$. The correlation coefficient observed between disease incidence and severity under field conditions was 0.58 , which is relatively high. However, the correlation coefficients observed between these traits and FDK were in a range of 0.29 to 0.32 , which are not very high. Finally, 
the correlations between disease severity measured in the greenhouse and the traits in the field were also relatively low, with correlation coefficients in a range of 0.32 to 0.35 .

Plant height and flowering date. High variation in plant height and flowering date was observed among the genotypes, and the frequency distributions of both traits were continuous. ANOVA also indicated significant differences among the genotypes for both traits (data not shown). The detailed phenotypic characterization of agronomic traits for the population was previously published (Malihipour et al. 2016).

Genetic linkage maps. Of the 323 SSR primer combinations screened on the parental DNA samples, 83 primer combinations amplified 96 polymorphic marker fragments. Those primers were used to evaluate the mapping population. Seven markers were discarded

Table 1. Parents values, population mean, ranges of recombinant inbred lines (RIL), and heritabilities for disease incidence, disease severity, and Fusariumdamaged kernels (FDK) using data collected from 230 recombinant inbred lines from the cross AC Brio/TC 67 under field and greenhouse conditions

\begin{tabular}{|c|c|c|c|c|c|}
\hline \multirow[b]{2}{*}{ Trait } & \multicolumn{2}{|c|}{ Parent value } & \multirow[b]{2}{*}{ Population mean } & \multirow[b]{2}{*}{ RIL range } & \multirow[b]{2}{*}{ Heritability } \\
\hline & AC Brio & TC 67 & & & \\
\hline \multicolumn{6}{|l|}{ Field } \\
\hline Disease incidence $(\%)$ & 43.5 & 24.3 & 37.6 & $14.4-64.5$ & 0.60 \\
\hline Disease severity (\%) & 42.1 & 41.3 & 50.6 & $27.0-75.5$ & 0.47 \\
\hline FDK $(\%)$ & 7.7 & 3.1 & 8.9 & $1.8-24.1$ & 0.67 \\
\hline \multicolumn{6}{|l|}{ Greenhouse } \\
\hline Disease severity (\%) & 34.9 & 4.9 & 34.5 & $4.8-94.9$ & 0.96 \\
\hline
\end{tabular}
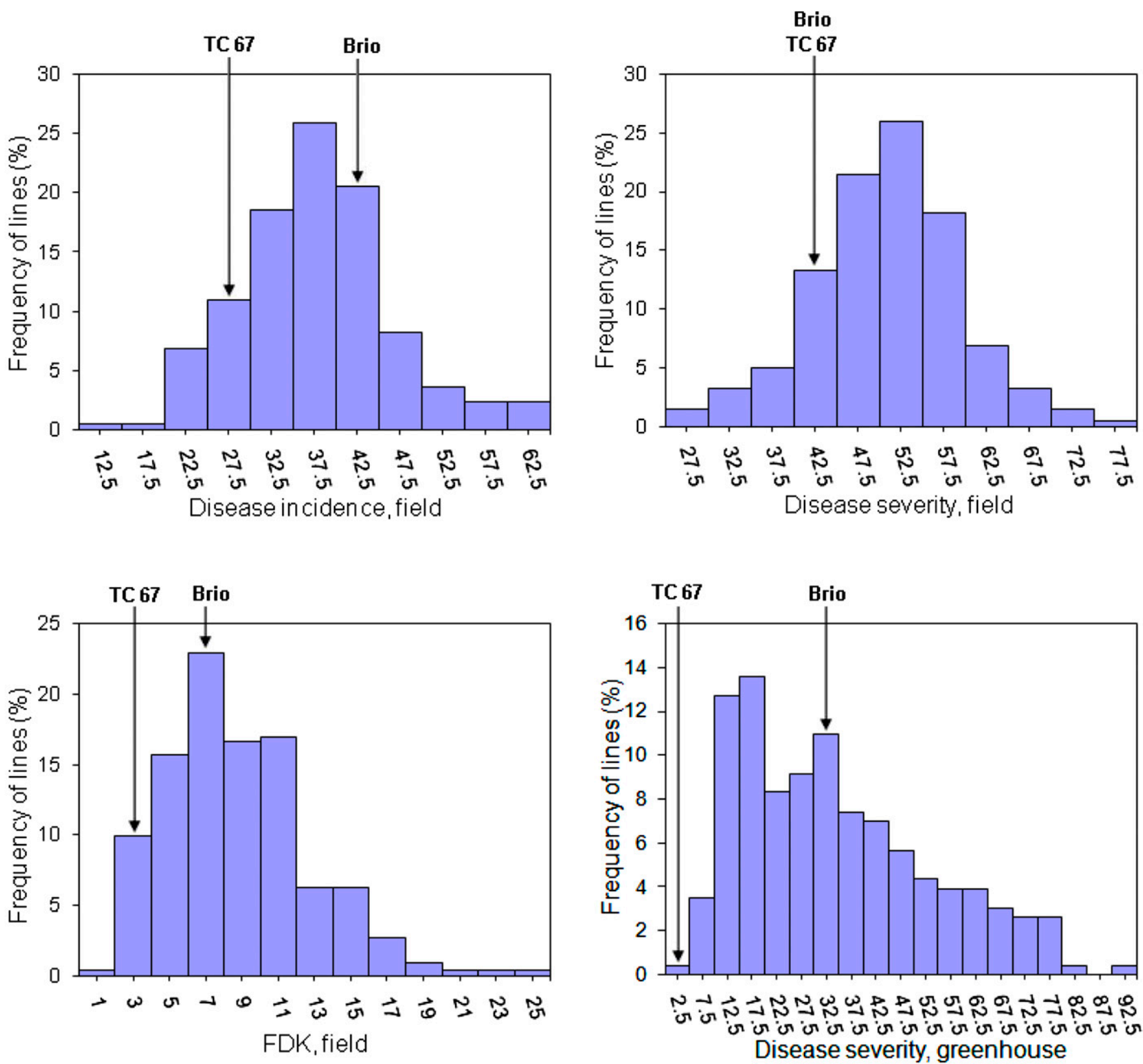

Fig. 1. Frequency distributions using data collected from 230 recombinant inbred lines from the cross AC Brio/TC 67 . Field data for disease incidence, disease severity, and Fusarium-damaged kernels (FDK) were collected from two locations in 2 years and disease severity in the greenhouse from two experiments. 
due to distorted segregation ratios, and the genotypic data of 89 markers from the mapping population were used to construct the genetic linkage maps. The genetic map, which was subsequently used for QTL analysis, consisted of 17 linkage groups and comprised, in total, a length of $298.8 \mathrm{cM}$. The A genome was the most represented genome, with nine linkage groups, 55 molecular markers, and a length of $210.9 \mathrm{cM}$. Even though the SSR markers used in this study were originally from the A genome, the primer combinations of some of them amplified polymorphic marker fragments on the ' $\mathrm{B}$ ' genome. As a result, one linkage group with four molecular markers and a total length of $21.9 \mathrm{cM}$ was assigned to the B genome. However, no marker or linkage group was located to the ' $D$ ' genome. In the present study, seven linkage groups consisting of 18 markers could not be assigned clearly to one specific chromosome. In addition, 12 markers remained unlinked. The average distance between markers in the linkage groups was $3.9 \mathrm{cM}$ in this investigation.

QTL mapping. Multiple interval mapping using QGene detected two major QTL on chromosome arm 5AL and another one on chromosome 6A for resistance to FHB (Table 2; Fig. 2). Another minor QTL for FHB resistance was also identified in the present study (data not shown). On the other hand, several QTL for agronomic traits were mapped, including one and two minor QTL for plant height on chromosomes 2A and 5A, respectively, and a major QTL for plant height and a minor one for flowering date, both mapped to chromosome 6A (Table 2; Fig. 2).

The 5AL QTL detected in the marker interval of $c f d 6.1$-barc48 (closest marker $c f d 6.1$ ) was associated with disease incidence (type I resistance) under field conditions. This QTL accounted for $10.9 \%$ of phenotypic variation for this trait, with an additive effect of -0.04 . This QTL also had small effects on disease severity (type I + type II resistance) and FDK (type IV resistance) under field conditions. The second QTL mapped to this chromosome, in the marker interval of $c f d 39-c f a 2185$ (closest marker $c f a 2185$ ), was associated with FDK in the field and disease severity in the greenhouse, explaining 19.4 and $20.6 \%$ of phenotypic variation for these traits, respectively. The additive effects of this QTL were -0.04 and -0.13 , respectively. The two 5AL QTL were approximately $30 \mathrm{cM}$ apart on the chromosome and the alleles from TC 67 were associated with resistance. In addition, the closest markers to either of these QTL shared the same pattern and size of alleles in TC 67 and its resistant parent, $T$. timopheevii (data not shown). The QTL mapped in the marker interval of gwm132.1-wmc621 (closest marker wmc621) on chromosome 6A was associated with disease severity in the greenhouse, explaining $11.8 \%$ of phenotypic variation, with an additive effect of 0.08 . This genomic region was associated with resistance to disease incidence and severity under field conditions, accounting for 6.8 and $10.1 \%$ of phenotypic variation for these traits, respectively. The allele from AC Brio in this chromosome region contributed to reduced disease incidence and severity under field conditions. Pattern and size of alleles for the closest markers to either of the 6A QTL were identical in AC Brio and the susceptible parent of TC 67, Crocus (data not shown). In the present study, a minor QTL associated with disease severity in the greenhouse, linked to the marker barc154.1, was also detected (data not shown). However, the linkage group associated with this QTL could not be assigned to a chromosome.

The 2A QTL detected in the marker interval of gwm275-gwm95 (closest marker $g w m 95$ ) explained $5.8 \%$ of phenotypic variation for plant height using field data, with an additive effect of -0.01 . For this QTL, the TC 67 allele reduced plant height even though this is the tall parent in the cross. The 5AL QTL detected in the marker interval of $c f a 2185$-cfa2141 (closest marker $c f a 2141$ ) explained $6.4 \%$ of phenotypic variation for plant height using field data, with an additive effect of 0.01. Similarly, the QTL in the marker interval of gwm666.1-barc151 (closest marker gwm666.1) from this chromosome accounted for $7.0 \%$ of phenotypic variation for plant height using greenhouse data, with an additive effect of 0.01 . For both of these QTL, the alleles for tall stature came from resistant parent TC 67. Two QTL for agronomic traits were also mapped to chromosome 6A, of which the QTL detected in the marker interval of $c f d 80$-wmc748 (closest marker $c f d 80$ ) explained $9.9 \%$ of phenotypic variation for plant height, with an additive effect of 0.02 . The second 6A QTL, detected in the marker interval of wmc621-cfd6.2 (closest marker wmc621), accounted for $5.5 \%$ of phenotypic variation for flowering date, with an additive effect of 0.01 . The alleles for tall stature and late flowering for these QTL, respectively, were from the resistant parent TC 67.

The combined QTL in the marker intervals of $c f d 6.1$-barc48 from 5AL and gwm132.1-wmc621 from 6A explained $17.7 \%$ of phenotypic variation for disease incidence under field conditions or type I resistance. These QTL also explained $15.3 \%$ of phenotypic variation for disease severity under field conditions, which represents a combination of type I and type II or overall field resistance. In addition, the QTL in the marker intervals of $c f d 6.1$-barc48 and $c f d 39$ cfa2185 from chromosome 5AL together explained $27.2 \%$ of

Table 2. Quantitative trait loci (QTL) analysis of Fusarium head blight (FHB) resistance by multiple interval mapping for disease incidence, disease severity, and Fusarium-damaged kernels (FDK) using data collected from 230 recombinant inbred lines from the cross AC Brio/TC 67 under field and greenhouse conditions

\begin{tabular}{|c|c|c|c|c|c|c|c|c|}
\hline Trait, chromosome & Marker interval & Closest marker & Trait $^{\mathbf{a}}$ & LOD thrsd ${ }^{b}$ & LOD & $R^{2}(\%)$ & Additive effect ${ }^{c}$ & Donor parent ${ }^{\mathrm{d}}$ \\
\hline \multicolumn{9}{|l|}{ FHB resistance } \\
\hline $5 \mathrm{AL}$ & cfd6.1-barc48 & $c f d 6.1$ & DI (F) & 2.13 & 5.75 & 10.9 & -0.04 & TC 67 \\
\hline $5 \mathrm{AL}$ & cfd6.1-barc 48 & $c f d 6.1$ & DS (F) & 2.09 & 2.65 & 5.2 & -0.02 & TC 67 \\
\hline $5 \mathrm{AL}$ & cfd6.1-barc 48 & $c f d 6.1$ & FDK $(\mathrm{F})$ & 2.09 & 4.03 & 7.8 & -0.02 & TC 67 \\
\hline $5 \mathrm{AL}$ & $c f d 39-c f a 2185$ & $c f a 2185$ & FDK $(\mathrm{F})$ & 2.09 & 10.75 & 19.4 & -0.04 & TC 67 \\
\hline $5 \mathrm{AL}$ & $c f d 39-c f a 2185$ & $c f a 2185$ & DS (G) & 2.18 & 11.50 & 20.6 & -0.13 & TC 67 \\
\hline $6 \mathrm{~A}$ & gwm132.1-wmc621 & gwm132.1 & DI (F) & 1.52 & 3.50 & 6.8 & +0.03 & AC Brio \\
\hline $6 \mathrm{~A}$ & gwm132.1-wmc621 & gwm132.1 & DS (F) & 1.57 & 5.32 & 10.1 & +0.03 & AC Brio \\
\hline $6 \mathrm{~A}$ & gwm132.1-wmc621 & wmc621 & DS (G) & 1.49 & 6.26 & 11.8 & +0.08 & AC Brio \\
\hline \multicolumn{9}{|l|}{ Agronomic } \\
\hline $2 \mathrm{~A}$ & gwm275-gwm 95 & gwm 95 & PH (F) & 1.79 & 3.00 & 5.8 & -0.01 & AC Brio \\
\hline $5 \mathrm{AL}$ & $c f a 2185-c f a 2141$ & $c f a 2141$ & $\mathrm{PH}(\mathrm{F})$ & 2.02 & 3.29 & 6.4 & +0.01 & TC 67 \\
\hline $5 \mathrm{AL}$ & gwm666.1-barc151 & gwm666.1 & $\mathrm{PH}(\mathrm{G})$ & 2.04 & 3.61 & 7.0 & +0.01 & TC 67 \\
\hline $6 \mathrm{~A}$ & $c f d 80-w m c 748$ & $c f d 80$ & $\mathrm{PH}(\mathrm{G})$ & 1.46 & 5.19 & 9.9 & +0.02 & TC 67 \\
\hline $6 \mathrm{~A}$ & wmc621-cfd6.2 & wmc621 & FD (G) & 1.34 & 2.85 & 5.5 & +0.01 & TC 67 \\
\hline
\end{tabular}

a Abbreviations: DI = disease incidence, DS = Disease severity, F indicates field data based on combined data of two locations in 2 years, $\mathrm{G}$ refers to the greenhouse data, $\mathrm{PH}=$ plant height, and FD = flowering date.

${ }^{\mathrm{b}}$ Logarithm of odds (LOD) threshold, estimation using a permutation test of $n=1,000$ at $P<0.05$.

${ }^{c}$ Negative values for the additive effects of Fusarium head blight QTL indicate that the TC 67 allele reduces the average trait values relative to the AC Brio allele. Positive values for the additive effects of agronomic trait QTL indicate that the TC 67 allele increases the average trait values relative to the AC Brio allele.

${ }^{d}$ Alleles from the donor parent confers lower disease incidence and disease severity, fewer FDK, taller plants, and later flowering date under field conditions or in the greenhouse. 
phenotypic variation for FDK or type IV resistance. Furthermore, the 5AL QTL in the marker interval of $c f d 39-c f a 2185$ and the 6A QTL in the marker interval of gwm132.1-wmc621 together explained $32.4 \%$ of the phenotypic variation for disease severity in the greenhouse. On the other hand, the QTL conferring agronomic traits mapped to the chromosomes $2 \mathrm{~A}, 5 \mathrm{AL}$, and $6 \mathrm{~A}$ all together explained $29.1 \%$ of phenotypic variation for plant height, whereas the only QTL from 6A conferring flowering date accounted for $5.5 \%$ of phenotypic variation for this trait.

\section{Discussion}

Transgressive segregation was observed among the RIL for all traits measured. Presence of transgressive segregation in this study indicates that neither of the parents carries a full complement of resistance QTL or genes. It also suggests that improvements in FHB resistance can be made by combining resistance genes from different parents (Somers et al. 2003). However, there were very few transgressive segregants with lower disease severity than the resistant parent in the greenhouse study. This suggests that identifying recombinants that are better than the best parent for all traits may be difficult. Transgressive segregation is a common phenomenon in FHB resistance and has been discussed in published literature (Bai and Shaner 1994; Buerstmayr et al. 2000; Ghavami et al. 2011; Malla et al. 2010; Somers et al. 2006). In addition, reports have indicated that resistance alleles sometimes contributed to transgressive segregation by a susceptible parent (Liu et al. 2005; Snijders 1990; Waldron et al. 1999). Obtaining transgressive segregants from a cross between a resistant and a susceptible variety is beneficial for breeders.

The moderate to high heritability of traits measured in different environments showed that there was high genetic variability for the traits facilitating QTL detection. By better expression of genetic effects, uniform environmental conditions in the greenhouse were conducive to a high value of heritability for the resistance trait. In contrast, the interaction effects of year-genotype or year-location-genotype might have contributed to reduce the values of heritability for some traits under field conditions. Despite the high influence of environment on expression of the resistance traits, QTL could be consistently identified.

The correlation observed between disease incidence measured under field conditions and disease severity assessed in the greenhouse was not high. This was to be expected because each trait represented a specific type of resistance (i.e., type I and type II, respectively). In contrast, the relatively high positive correlation coefficient observed between disease incidence and severity under field conditions demonstrates that these measurements are interrelated under field conditions. Our findings are consistent with the results of Steiner et al. (2004), who observed a high positive correlation between FHB incidence and severity. However, the correlation coefficients observed between these traits and FDK were not very high. Because FDK is a measure of type IV resistance (Mesterházy 1995; Mesterházy et al. 1999), it is possible that there is different genetic control for FDK than for disease incidence or severity under field conditions.

Chromosome 5A has been found to be involved in FHB resistance in widely diverse wheat germplasm, and QTL from this chromosome have been reported for type I and type II resistance, low FDK, and low DON content (Buerstmayr et al. 2009). In the present study, two stable QTL conferring resistance to FHB were mapped to the chromosome arm 5AL; both conferred resistance to more than one resistance trait. The QTL detected in the marker interval of $c f d 39-c f a 2185$ showed the highest effects on disease severity in the greenhouse (type II resistance) and FDK under field conditions (type IV resistance). The effect of a genomic region on more than one trait may be attributed to the presence of a pleiotropic QTL conferring resistance to different traits, or to the presence of more than one overlapping QTL in one position. There are several reports discussing pleiotropic effects of a QTL on more than one trait or the presence of overlapping QTL in wheat populations. In their study of a population of 'W14'/'Pioneer Brand 2684', Chen et al. (2006) detected a 5AS QTL which explained phenotypic variation for FHB incidence and severity, DON accumulation, and FDK. A QTL on chromosome 5A for reduced DON accumulation and type II resistance was also reported in the cross of Wangshuibai/'Annong 8455' (Ma et al. 2006b). In addition, in a population of wheat from the cross Frontana/'Remus', SzabóHevér et al. (2012) identified a QTL on chromosome 5A which conferred resistance to both disease severity and FDK. Therefore, there should be at least one QTL in each position of the 5AL conferring resistance to one or more FHB resistance traits in the population we studied. However, the chance of the presence of more than one overlapping QTL in one genomic region is not impossible.

Because the pattern and size of the closest markers to either of the 5AL QTL were identical in TC 67 and its resistant parent T. timopheevii, both of these QTL should have come from T. timopheevii. To date, no QTL for resistance to FHB has been reported from T. timopheevii. In addition, while most 5A QTL for FHB resistance reported from other wheat species are located in the range of 30 to $90 \mathrm{cM}$ (Buerstmayr et al. 2009) and another QTL in the range of 146 to $167 \mathrm{cM}$ (Buerstmayr et al. 2011), the QTL detected in the marker interval of $c f d 39-c f a 2185$ in this investigation was located in a range of 103 to $142 \mathrm{cM}$, based on microsatellite consensus map (Schuelke 2000; Somers et al. 2004). Therefore, we assume that this QTL differs from the previously reported QTL at this chromosome. We conclude that the QTL mapped to this marker interval from the chromosome arm 5AL is a novel QTL. However, the novelty of the 5AL QTL in the marker interval of cfd6.1-barc48 cannot be proved using the available data.

In the present study, another QTL for FHB resistance was mapped in the marker interval of gwm132.1-wmc621 to chromosome 6A, with minor effects on disease incidence (field) and major effects on disease severity (field and greenhouse). It is possible that there is only one pleiotropic QTL present in this marker position conferring resistance to several traits. Chromosome 6A is not widely used in FHB resistance in wheat. However, there are a few reports indicating a role of this chromosome in increasing type II resistance and lowering disease severity in wheat (Anderson et al. 2001; Buerstmayr et al. 2012; Ma et al. 2006a; Schmolke et al. 2005). It is not clear from our data if there is association between the QTL detected in this population and those previously reported. However, it is the first time that a 6A QTL with an effect on disease incidence is reported. The closest markers to either of the 6A QTL which came from the moderately susceptible parent AC Brio shared a common allele with the susceptible parent of TC 67, Crocus. It is possible that this similarity is due to genetic relatedness between these hexaploid wheat cultivars, because both Crocus and AC Brio have a common background of Columbus.

Several QTL for plant height on the chromosomes 2A, 5A, and 6A and a QTL for flowering date on chromosome $6 \mathrm{~A}$ were also detected in the present investigation. There are many reduced height $(R h t)$ genes identified for reduction of plant height in wheat such as $R h t$ Blb (Rht1), Rht-D1b (Rht2), and Rht8 (Worland et al. 1998). In addition, all wheat chromosomes carry genes for flowering date, including vernalization response $(V r n)$, photoperiod response $(P p d)$, and "earliness per se" (Eps) genes (Snape et al. 2001). However, plant height and heading date may be controlled by different QTL in different crops (Börner et al. 2002; Shindo et al. 2003; Xu et al. 2005; Zhang et al. 2009). Several QTL for plant height have been previously reported from several chromosomes, including $2 \mathrm{~A}, 5 \mathrm{~A}$, and 6A (Buerstmayr et al. 2011; Griffiths et al. 2009, 2012; Liu et al. 2011; Peng et al. 2011). QTL for flowering date have also been reported from chromosome 6A (Kamran et al. 2013). However, there is no evidence for the association between the QTL for plant height and flowering date detected in the present study and the QTL previously reported. In addition, even though plant height and flowering date both showed negative associations with disease incidence and severity or positive associations with FDK under field conditions (Malihipour et al. 2016), the association between these agronomic QTL and the FHB QTL detected in the present population cannot be determined. Detailed mapping of the FHB resistance QTL as well as the linked QTL determining important agronomic characteristics is necessary in order to make significant progress in FHB resistance (Chrpová et al. 2011).

Mapping QTL using microsatellite markers in the present population detected several QTL for FHB resistance, of which two QTL from chromosome 5AL and two from chromosome $6 \mathrm{~A}$ all were stable QTL with major effects on FHB resistance. The QTL mapped in the marker 
interval of cfd39-cfa2185 from chromosome 5AL is a novel QTL originating from $T$. timopheevii, which is reported here for the first time. The QTL mapped in the present study along with other well-known QTL in wheat breeding programs should be useful for enhancing the level of resistance to FHB in wheat cultivars. T. timopheevii is considered a source of resistance not only for FHB but also for several important diseases of wheat such as common root rot (Bailey et al. 1993), stem rust (Allard and Shands 1954), leaf rust (Leonova et al. 2007), powdery mildew (Peusha et al. 1995), and Septoria nodorum blotch (Ma and Hughes 1995). Several genes for resistance to leaf rust have been transferred to common wheat from diverse accessions of T. timopheevii; of these, Lrl8 (Dyck and Samborski 1968) and Lr50 (Brown-Guedira et al. 2003) are noteworthy. Therefore, transfer and use of T. timopheevii QTL in wheat germplasm may enhance

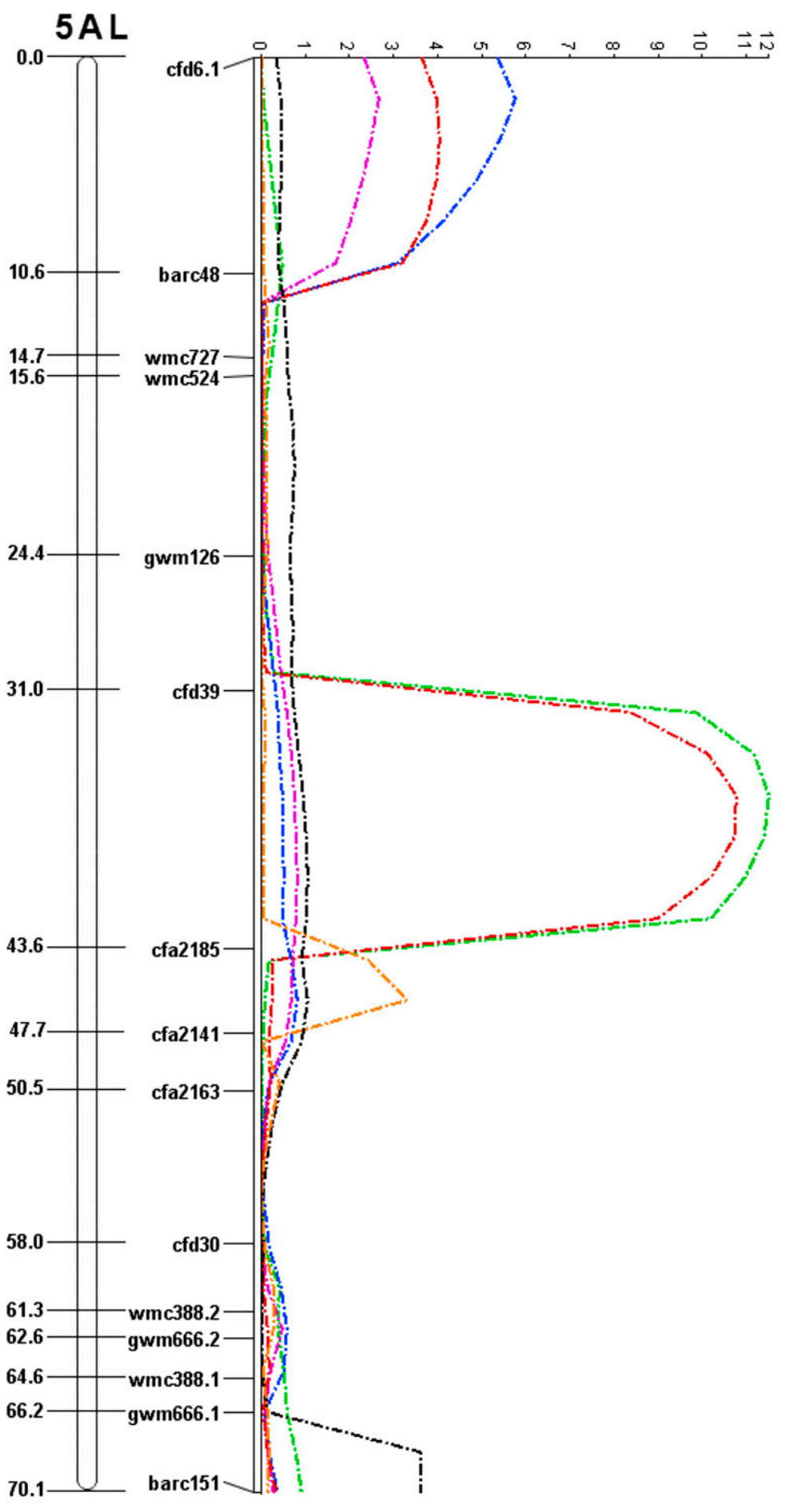

\section{Legend}

Disease incidence (field)

Disease severity (field)

FDK (field)

Disease severity (greenhouse)

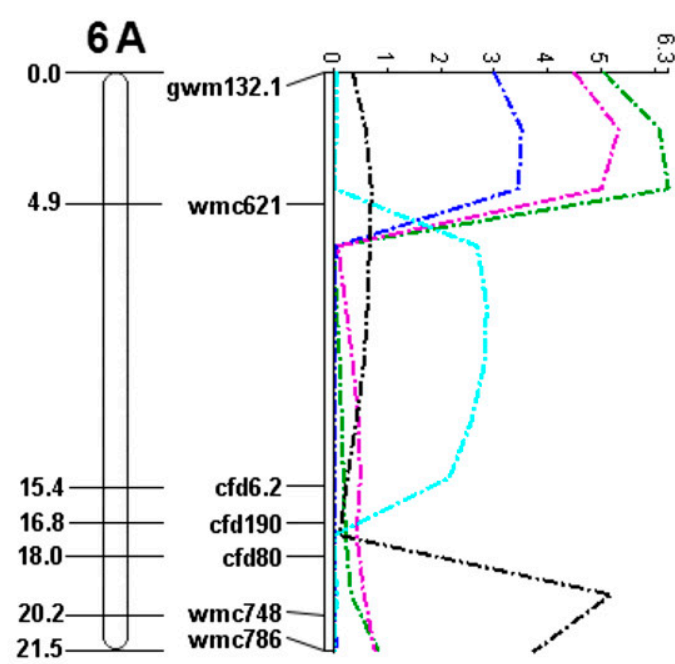

$2 \mathrm{~A}$

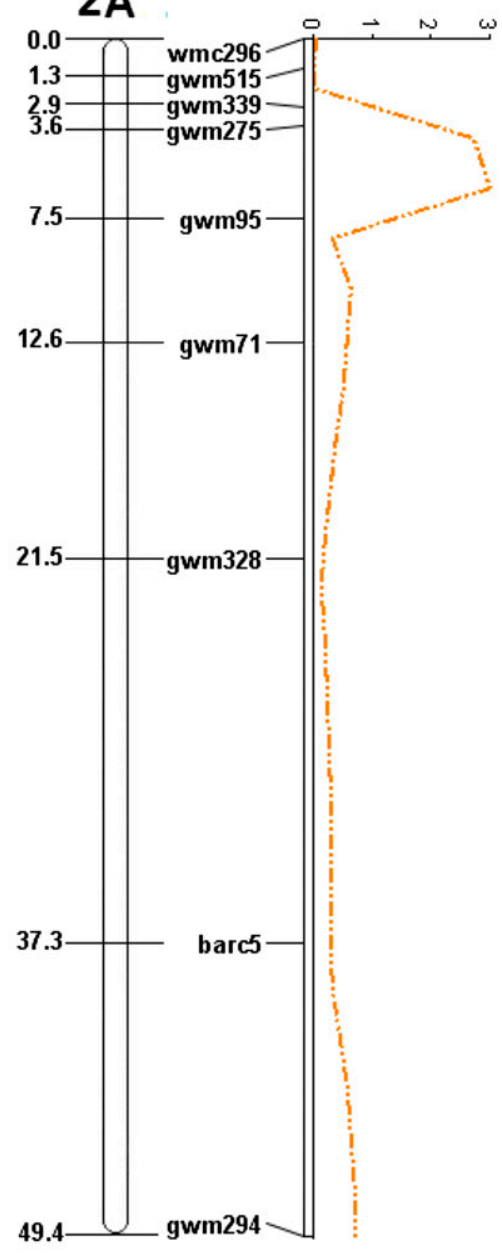

Fig. 2. Linkage maps and logarithm of odds curves after multiple interval mapping using data collected from 230 recombinant inbred lines from the cross AC Brio/TC 67 . Field data were collected from two locations in 2 years and the greenhouse from two experiments. 
resistance to other diseases as well. However, the negative correlation between FHB and undesirable agronomic traits such as plant height (Malihipour et al. 2016) may impede breeding wheat for resistance to FHB using TC 67 QTL. In addition, the FHB resistance QTL and their linked markers must be validated by examining the segregation of markers with QTL in different genetic backgrounds.

Even though the QTL detected in the present study explained a high proportion of phenotypic variation for FHB resistance traits, there are gaps between the proportion of phenotypic variation that is potentially due to genetic effects and the amount of phenotypic variation explained by the genetic factors (QTL). One possible explanation is incomplete coverage of our genetic map from the A and B genomes, which may hamper the detection of one or several QTL with strong effects. In addition, genetic factors affecting FHB resistance may be present on the $\mathrm{D}$ genome, which was not mapped in this study. Even though a few minor QTL were detected in the present population, the effect of undetected ones may also be mentioned. Detection and use of the QTL not identified yet from this population may be of great importance to complete the study.

\section{Acknowledgments}

The Ph.D. fellowship of A. Malihipour was supported by the Agricultural Research, Education, and Extension Organization, Ministry of Agriculture, Iran. Other expenses of this research were funded through the CRC, Agriculture and Agri-Food Canada. We thank S. Woods for her comments regarding experimental design and data analysis; D. Somers for providing the facilities for microsatellite analysis; and R. Kaethler, K. Slusarenko, U. Kromer, T. Unrau, A. Walichnowski, L. Bezte, A. Brown, and R. Larios for technical assistance in the laboratory and field.

\section{Literature Cited}

Afshari-Azad, H. 1992. Produktion Extracellularer, Hydrolytischer Enzyme von Pseudocercosporella herpotrichoides (Fron) Deighton, Fusarium culmorum (W. G. Smith) Sacc. sowie Rhizoctonia cerealis in vitro bzw. in planta und ihre Beziehung zur Pathogenese. Georg-August-Universitaet Göttingen, Göttingen, Germany.

Allard, R. W., and Shands, R. G. 1954. Inheritance of resistance to stem rust and powdery mildew in cytologically stable spring wheats derived from Triticum timopheevii. Phytopathology 44:266-274.

Anderson, J. A., Stack, R. W., Liu, S., Waldron, B. L., Fjeld, A. D., Coyne, C., Moreno-Sevilla, B., Fetch, J. M., Song, Q. J., Cregan, P. B., and Frohberg, R. C. 2001. DNA markers for Fusarium head blight resistance QTLs in two wheat populations. Theor. Appl. Genet. 102:1164-1168.

Bai, G.-H., Kolb, F. L., Shaner, G., and Domier, L. L. 1999. Amplified fragment length polymorphism markers linked to a major quantitative trait locus controlling scab resistance in wheat. Phytopathology 89:343-348.

Bai, G.-H., and Shaner, G. 1994. Scab of wheat: Prospects for control. Plant Dis. 78:760-766.

Bai, G.-H., and Shaner, G. E. 2004. Management and resistance in wheat and barley to Fusarium head blight. Annu. Rev. Phytopathol. 42:135-161.

Bailey, K. L., Harding, H., and Knott, D. R. 1993. Transfer to bread wheat of resistance to common root rot (Cochliobolus sativus) identified in Triticum timopheevii and Aegilops ovata. Can. J. Plant Pathol. 15:211-219.

Benham, J., Jeung, J. U., Jasieniuk, M., Kanazin, V., and Blake, T. 1999. Genographer: a graphical tool for automated AFLP and microsatellite analysis. J. Agric. Genom. 4:3.

Börner, A., Schumann, E. A. F., Cöster, H., Leithold, B., Röder, M. S., and Weber, W. E. 2002. Mapping of quantitative trait loci determining agronomic important characters in hexaploid wheat (Triticum aestivum L.). Theor. Appl. Genet. 105: 921-936.

Brown-Guedira, G. L., Singh, S., and Fritz, A. K. 2003. Performance and mapping of leaf rust resistance transferred to wheat from Triticum timopheevii subsp. armeniacum. Phytopathology 93:784-789.

Buerstmayr, H., Ban, T., and Anderson, J. A. 2009. QTL mapping and markerassisted selection for Fusarium head blight resistance in wheat: A review. Plant Breed. 128:1-26.

Buerstmayr, H., Steiner, B., Hartl, L., Griesser, M., Angerer, N., Lengauer, D., Miedaner, T., Schneider, B., and Lemmens, M. 2003a. Molecular mapping of QTLs for Fusarium head blight resistance in spring wheat. II. Resistance to fungal penetration and spread. Theor. Appl. Genet. 107:503-508.

Buerstmayr, H., Steiner, B., Lemmens, M., and Ruckenbauer, P. 2000. Resistance to Fusarium head blight in winter wheat: Heritability and trait associations. Crop Sci. 40:1012-1018.

Buerstmayr, H., Stierschneider, M., Steiner, B., Lemmens, M., Griesser, M., Nevo, E., and Fahima, T. 2003b. Variation for resistance to head blight caused by Fusarium graminearum in wild emmer (Triticum dicoccoides) originating from Israel. Euphytica 130:17-23.

Buerstmayr, M., Huber, K., Heckmann, J., Steiner, B., Nelson, J. C., and Buerstmayr, H. 2012. Mapping of QTL for Fusarium head blight resistance and morphological and developmental traits in three backcross populations derived from Triticum dicoccum $\times$ Triticum durum. Theor. Appl. Genet. 125:1751-1765.

Buerstmayr, M., Lemmens, M., Steiner, B., and Buerstmayr, H. 2011. Advanced backcross QTL mapping of resistance to Fusarium head blight and plant morphological traits in a Triticum macha $\times T$. aestivum population. Theor. Appl. Genet. 123:293-306.

Cai, X., Chen, P. D., Xu, S. S., Oliver, R. E., and Chen, X. 2005. Utilization of alien genes to enhance Fusarium head blight resistance in wheat-A review. Euphytica 142:309-318.

Cao, W., Fedak, G., Armstrong, K., Xue, A., and Savard, M. E. 2009. Registration of spring wheat germplasm TC 67 resistant to Fusarium head blight. J. Plant Regist. 3:104-106.

Chen, J., Griffey, C. A., Liu, S., Saghai-Maroof, M. A., Murphy, J. P., Navarro, R. A., Sneller, C. H., Brown-Guedira, G. L., and Souza, E. J. 2012. Registration of Fusarium head blight-resistant soft red winter wheat germplasm VA04W-433 and VA04W-474. J. Plant Regist. 6:111-116.

Chen, J., Griffey, C. A., Saghai-Maroof, M. A. S., Stromberg, E. L., Biyashev, R. M., Zhao, W., Chappell, M. R., Pridgen, T. H., Dong, Y., and Zeng, Z. 2006. Validation of two major quantitative trait loci for Fusarium head blight resistance in Chinese wheat line W14. Plant Breed. 125:99-101.

Chen, P., Liu, W., Yuan, J., Wang, X., Zhou, B., Wang, S., Zhang, S., Feng, Y., Yang, B., Liu, G., Liu, D., Qi, L., Zhang, P., Friebe, B., and Gill, B. S. 2005 Development and characterization of wheat- Leymus racemosus translocation lines with resistance to Fusarium head Blight. Theor. Appl. Genet. 111:941-948.

Chrpová, J., Šíp, V., Sedláček, T., Štočková, L., Veškrna, O., and Horčička, P. 2011. Effectiveness of marker-based selection for Fusarium head blight resistance in spring wheat. Czech J. Genet. Plant Breed. (Special Issue) 47:S123-S129.

Churchill, G. A., and Doerge, R. W. 1994. Empirical threshold values for quantitative trait mapping. Genetics 138:963-971.

Dyck, P. L., and Samborski, D. J. 1968. Host-parasite interactions involving two genes for leaf rust resistance in wheat. Pages 245-250 in: Third Int. Wheat Genet. Symp. K. W. Finlay and K. W. Shepherd, eds. Australian Academy of Science, Canberra, ACT, Australia.

Fox, S. L., Thomas, J. B., Wise, I. L., Smith, M. A. H., Humphreys, D. G., Brown, P. D., Townley-Smith, T. F., McCallum, B. D., Fetch, T. G., Menzies, J. G., Gilbert, J. A., Fernandez, M. R., Despins, T., and Niziol, D. 2009. Waskada hard red spring wheat. Can. J. Plant Sci. 89:929-936.

Frohberg, R. C., Stack, R. W., and Mergoum, M. 2004. Registration of spring wheat germplasm ND2710 resistant to Fusarium head blight. Crop Sci. 44: 1468-1469.

Ghavami, F., Elias, E. M., Mamidi, S., Ansari, O., Sargolzaei, M., Adhikari, T., Mergoum, M., and Kianian, S. F. 2011. Mixed model association mapping for Fusarium head blight resistance in Tunisian-derived durum wheat populations. G3 Genes Genomes Genet. 1:209-218.

Griffiths, S., Simmonds, J., Leverington, M., Wang, Y., Fish, L., Sayers, L., Alibert, L. Orford, S., Wingen, L., Herry, L., Faure, S., Laurie, D., Bilham, L., and Snape, J. 2009. Meta-QTL analysis of the genetic control of ear emergence in elite European winter wheat germplasm. Theor. Appl. Genet. 119:383-395.

Griffiths, S., Simmonds, J., Leverington, M., Wang, Y., Fish, L., Sayers, L., Alibert, L., Orford, S., Wingen, L., and Snape, J. 2012. Meta-QTL analysis of the genetic control of crop height in elite European winter wheat germplasm. Mol. Breed. 29:159-171.

Gupta, P., Balyan, H., Edwards, K., Isaac, P., Korzun, V., Roeder, M., Gautier M.-F., Joudrier, P., Schlatter, A., Dubcovsky, J., De la Pena, R., Khairallah, M. Penner, G., Hayden, M., Sharp, P., Keller, B., Wang, R., Hardouin, J., Jack, P., and Leroy, P. 2002. Genetic mapping of 66 new microsatellite (SSR) loci in bread wheat. Theor. Appl. Genet. 105:413-422.

Guyomarc'h, H., Sourdille, P., Charmet, G., Edwards, K. J., and Bernard, M. 2002 Characterisation of polymorphic microsatellite markers from Aegilops tauschii and transferability to the D-genome of bread wheat. Theor. Appl. Genet. 104: 1164-1172.

Hallauer, A. R., and Miranda, J. B. 1981. Quantitative Genetics in Maize Breeding. Iowa State University Press, Ames IA

Jia, G., Chen, P., Qin, G., Bai, G., Wang, X., Wang, S., Zhou, B., Zhang, S., and Liu, D. 2005. QTLs for Fusarium head blight response in a wheat DH population of Wangshuibai/Alondra's'. Euphytica 146:183-191.

Jiang, G.-L., Dong, Y., Shi, J., and Ward, R. W. 2007. QTL analysis of resistance to Fusarium head blight in the novel wheat germplasm CJ 9306. II. Resistance to deoxynivalenol accumulation and grain yield loss. Theor. Appl. Genet. 115: 1043-1052.

Joehanes, R., and Nelson, J. C. 2008. QGene 4.0, an extensible Java QTL-analysis platform. Bioinformatics 24:2788-2789.

Kamran, A., Iqbal, M., Navabi, A., Randhawa, H., Pozniak, C., and Spaner, D. 2013. Earliness per se QTLs and their interaction with the photoperiod insensitive allele Ppd-D1a in the Cutler $\times$ AC Barrie spring wheat population. Theor. Appl. Genet. 126:1965-1976.

Kosambi, D. D. 1943. The estimation of map distance from recombination values. Ann. Eugen. 12:172-175.

Lemmens, M., Scholz, U., Berthiller, F., Dall'Asta, C., Koutnik, A., Schuhmacher R., Adam, G., Buerstmayr, H., Mesterházy, A., Krska, R., and Ruckenbauer, P. 2005. The ability to detoxify the mycotoxin deoxynivalenol colocalizes with a major quantitative trait locus for Fusarium head blight resistance in wheat. Mol. Plant-Microbe Interact. 18:1318-1324. 
Leonova, I. N., Laikova, L. I. , Popova, O. M., Unger, O., Börner, A., and Röder, M. S. 2007. Detection of quantitative trait loci for leaf rust resistance in wheat T. timopheevii. Euphytica 155:79-86.

Lin, F., Xue, S. L., Zhang, Z. Z., Zhang, C. Q., Kong, Z. X., Yao, G. Q., Tian, D. G., Zhu, H. L., Li, C. J., Cao, Y., Wei, J. B., Luo, Q. Y., and Ma, Z. Q. 2006. Mapping QTL associated with resistance to Fusarium head blight in the Nanda2419 $\times$ Wangshuibai population. II: Type I resistance. Theor. Appl. Genet. 112:528-535.

Liu, G., Xu, S. B., Ni, Z. F., Xie, C. J., Qin, D. D., Li, J., Lu, L. H., Zhang, J. P., Peng, H. R., and Sun, Q. X. 2011. Molecular dissection of plant height QTLs using recombinant inbred lines from hybrids between common wheat (Triticum aestivum L.) and spelt wheat (Triticum spelta L.). Chin. Sci. Bull. 56:1897-1903

Liu, S., Abate, Z. A., and McKendry, A. L. 2005. Inheritance of Fusarium head blight resistance in the soft red winter wheat Ernie. Theor. Appl. Genet. 110: 454-461.

Liu, S., Zhang, X., Pumphrey, M. O., Stack, R. W., Gill, B. S., and Anderson, J. A. 2006. Complex microcolinearity among wheat, rice, and barley revealed by fine mapping of the genomic region harboring a major QTL for resistance to Fusarium head blight in wheat. Funct. Integr. Genomics 6:83-89.

Ma, H., and Hughes, G. R. 1995. Genetic control and chromosomal location of Triticum timopheevii derived resistance to septoria nodorum blotch in durum wheat. Genome 38:332-338.

Ma, H. X., Bai, G. H., Zhang, X., and Lu, W. Z. 2006a. Main effects, epistasis, and environmental interactions of quantitative trait loci for Fusarium head blight resistance in a recombinant inbred population. Phytopathology 96: 534-541.

Ma, H. X., Zhang, K. M., Gao, L., Bai, G. H., Chen, H. G., Cai, Z. X., and Lu, W. Z. 2006b. Quantitative trait loci for resistance to Fusarium head blight and deoxynivalenol accumulation in Wangshuibai wheat under field conditions. Plant Pathol. 55:739-745.

Malihipour, A., Gilbert, J., Fedak, G., Brûlé-Babel, A., and Cao, W. 2016. Characterization of agronomic traits in a population of wheat derived from Triticum timopheevii and their association with Fusarium head blight. Eur. J. Plant Pathol. 144:31-43.

Malla, S., Ibrahim, A. M. H., Yen, Y., Berzonsky, W., Glover, K. D., and Stein, J. 2010. Quantitative trait loci analysis of novel Fusarium head blight resistance in Tokai 66. Am. J. Agric. Biol. Sci. 5:62-69.

Mardi, M., Buerstmayr, H., Ghareyazie, B., Lemmens, M., Mohammadi, S. A., Nolz, R., and Ruckenbauer, P. 2005. QTL analysis of resistance to Fusarium head blight in wheat using a 'Wangshuibai'-derived population. Plant Breed. 124:329-333.

McMullen, M. P., Jones, R., and Gallenberg, D. 1997. Scab of wheat and barley: A re-emerging disease of devastating impact. Plant Dis. 81:1340-1348.

Mergoum, M., Frohberg, R. C., Miller, J. D., and Stack, R. W. 2005. Registration of 'Steele-ND' wheat. Crop Sci. 45:1163-1164.

Mergoum, M., Frohberg, R. C., Miller, J. D., Stack, R. W., Olsona, T., Friesen, T. L., and Rasmussen, J. B. 2006. Registration of 'Glenn' wheat. Crop Sci. 46: $473-474$

Mesterházy, A. 1989. Progress in breeding of wheat and corn genotypes not susceptible to infection by Fusaria. Pages 357-386 in: Fusarium: Mycotoxins, Taxonomy and Pathogenicity. J. Chelkowski, ed. Elsevier Science Publishers B.V., Amsterdam.

Mesterházy, A. 1995. Types and components of resistance to Fusarium head blight of wheat. Plant Breed. 114:377-386.

Mesterházy, A., Bartok, T., Mirocha, C. G., and Komoroczy, R. 1999. Nature of wheat resistance to Fusarium head blight and the role of deoxynivalenol for breeding. Plant Breed. 118:97-110.

Miller, J. D., Young, J. C., and Sampson, D. R. 1985. Deoxynivalenol and Fusarium head blight resistance in spring cereals. J. Phytopathol. 113: 359-367.

Oliver, R. E., Cai, X., Friesen, T. L., Halley, S., Stack, R. W., and Xu, S. S. 2008. Evaluation of Fusarium head blight resistance in tetraploid wheat (Triticum turgidum L.). Crop Sci. 48:213-222.

Oliver, R. E., Cai, X., Xu, S. S., Chen, X., and Stack, R. W. 2005. Wheat-alien species derivatives: A novel source of resistance to Fusarium head blight in wheat. Crop Sci. 45:1353-1360.

Oliver, R. E., Stack, R. W., Miller, J. D., and Cai, X. 2007. Reaction of wild emmer wheat accessions to Fusarium head blight. Crop Sci. 47:893-899.

Parry, D. W., Jenkinson, P., and McLeod, L. 1995. Fusarium ear blight (scab) in small grains-a review. Plant Pathol. 44:207-238.

Peng, J., Sun, D., and Nevo, E. 2011. Wild emmer wheat, Triticum dicoccoides, occupies a pivotal position in wheat domestication process. Aust. J. Crop Sci. 5:1127-1143.

Pestsova, E., Ganal, M. W., and Röder, M. S. 2000. Isolation and mapping of microsatellite markers specific for the D genome of bread wheat. Genome 43: 689-697.

Peusha, H. O., Stephan, U., Hsam, S. L. K., Felsenstein, F. G., Enno, T. M., and Zeller, F. J. 1995. Identification of genes for resistance to powdery mildew in common wheat (Triticum aestivum L.): IV. Breeding lines derived from wide crosses of Russian cultivars with species T. timopheevii Zhuk., T. militinae
Zhuk. et Migush., T. dicoccum (Schrank) Schuebl., and Aegilops speltoides Tausch. Genetika (Moscow) 31:212-218.

Röder, M. S., Korzun, V., Wendehake, K., Plaschke, J., Tixier, M.-H., Leroy, P., and Ganal, M. W. 1998. A microsatellite map of wheat. Genetics 149: 2007-2023.

Schmolke, M., Zimmermann, G., Buerstmayr, H., Schweizer, G., Miedaner, T., Korzun, V., Ebmeyer, E., and Hartl, L. 2005. Molecular mapping of Fusarium head blight resistance in the winter wheat population Dream/Lynx. Theor. Appl. Genet. 111:747-756.

Schroeder, H. W., and Christensen, J. J. 1963. Factors affecting resistance of wheat to scab caused by Gibberella zeae. Phytopathology 53:831-838.

Schuelke, M. 2000. An economic method for the fluorescent labeling of PCR fragments. Nat. Biotechnol. 18:233-234.

Shindo, C., Tsujimoto, H., and Sasakuma, T. 2003. Segregation analysis of heading traits in hexaploid wheat utilizing recombinant inbred lines. Heredity 90:56-63.

Snape, J. W., Butterworth, K., Whitechurch, E., and Worland, A. J. 2001. Waiting for fine times: Genetics of flowering time in wheat. Euphytica 119:185-190.

Snijders, C. H. A. 1990. Genetic variation for resistance to Fusarium head blight in bread wheat. Euphytica 50:171-179.

Somers, D. J., Fedak, G., Clarke, J., and Cao, W. 2006. Mapping of FHB resistance QTLs in tetraploid wheat. Genome 49:1586-1593.

Somers, D. J., Fedak, G., and Savard, M. 2003. Molecular mapping of novel genes controlling Fusarium head blight resistance and deoxynivalenol accumulation in spring wheat. Genome 46:555-564.

Somers, D. J., Isaac, P., and Edwards, K. 2004. A high-density microsatellite consensus map for bread wheat (Triticum aestivum L.). Theor. Appl. Genet. 109:1105-1114.

Song, Q. J., Fickus, E. W., and Cregan, P. B. 2002. Characterization of trinucleotide SSR motifs in wheat. Theor. Appl. Genet. 104:286-293.

Song, Q. J., Shi, J. R., Singh, S., Fickus, E. W., Costa, J. M., Lewis, J., Gill, B. S., Ward, R., and Cregan, P. B. 2005. Development and mapping of microsatellite (SSR) markers in wheat. Theor. Appl. Genet. 110:550-560.

Sourdille, P., Cadalen, T., Guyomarc'h, H., Snape, J. W., Perretant, M. R., Charmet, G., Boeuf, C., Bernard, S., and Bernard, M. 2003. An update of the Courtot $\times$ Chinese Spring intervarietal molecular marker linkage map for the QTL detection of agronomic traits in wheat. Theor. Appl. Genet. 106:530-538.

Steiner, B., Lemmens, M., Griesser, M., Scholz, U., Schondelmaier, J., and Buerstmayr, H. 2004. Molecular mapping of resistance to Fusarium head blight in the spring wheat cultivar Frontana. Theor. Appl. Genet. 109:215-224

Suzuki, T., Sato, M., and Takeuchi, T. 2012. Evaluation of the effects of five QTL regions on Fusarium head blight resistance and agronomic traits in spring wheat (Triticum aestivum L.). Breed. Sci. 62:11-17.

Szabó-Hevér, Á., Lehoczki-Krsjak, S., Tóth, B., Purnhauser, L., Buerstmayr, H., Steiner, B., and Mesterházy, A. 2012. Identification and validation of Fusarium head blight and Fusarium-damaged kernel QTL in a Frontana/ Remus DH mapping population. Can. J. Plant Pathol. 34:224-238.

Szabó-Hevér, Á., Lehoczki-Krsjak, S., Varga, M., Purnhauser, L., Pauk, J., Lantos, C., and Mesterházy, A. 2014. Differential influence of QTL linked to Fusarium head blight, Fusarium-damaged kernel, deoxynivalenol contents and associated morphological traits in a Frontana-derived wheat population. Euphytica 200:9-26.

Van Ooijen, J. W., and Voorrips, R. E. 2001. JoinMap 3.0 Software for the Calculation of Genetic Linkage Maps. Plant Research International, Wageningen, The Netherlands.

Waldron, B. L., Moreno-Sevilla, B., Anderson, J. A., Stack, R. W., and Frohberg, R. C. 1999. RFLP mapping of QTL for Fusarium head blight resistance in wheat. Crop Sci. 39:805-811.

Wang, Y.-Z., and Miller, J. D. 1988. Effects of Fusarium graminearum metabolites on wheat tissue in relation to Fusarium head blight resistance. J. Phytopathol. 122:118-125.

Worland, A. J., Krozun, V., Röder, M. S., Ganal, M. W., and Law, C. N. 1998 Genetic analysis of the dwarfing gene Rht8 in wheat. Part II. The distribution and adaptive significance of allelic variation at the Rht 8 locus of wheat as revealed by microsatellite screening. Theor. Appl. Genet. 96:1110-1120.

Xu, X., Bai, G. H., Carver, B. F., and Shaner, G. E. 2005. A QTL for early heading in wheat cultivar Suwon 92. Euphytica 146:233-237.

Yang, Z., Gilbert, J., Fedak, G., and Somers, D. J. 2005. Genetic characterization of QTL associated with resistance to Fusarium head blight in a doubled-haploid spring wheat population. Genome 48:187-196.

Yu, J.-B., Bai, G.-H., Zhou, W.-C., Dong, Y.-H., and Kolb, F. L. 2008. Quantitative trait loci for Fusarium head blight resistance in a recombinant inbred population of Wangshuibai/Wheaton. Phytopathology 98:87-94

Zadoks, J. C., Chang, T. T., and Konzak, F. C. 1974. A decimal code for growth stages of cereals. Weed Res. 14:415-421.

Zhang, K., Tian, J., Zhao, L., Lin, B., and Chen, G. 2009. Detection of quantitative trait loci for heading date based on the doubled haploid progeny of two elite Chinese wheat cultivars. Genetica 135:257-265.

Zhou, W. C., Kolb, F. L., Bai, G. H., Domier, L. L., and Yao, J. B. 2002. Effect of individual Sumai 3 chromosomes on resistance to scab spread within spikes and deoxynivalenol accumulation within kernels in wheat. Hereditas 137: 81-89. 